Egyptian

Orthodontic Journal

\title{
EVALUATION OF MODIFIED TANDEM APPLIANCE IN MANAGEMENT OF CASES WITH MAXILLARY RETRUSION
}

\author{
Yasser Lotfy Abdelnaby* Ahmad Mohammad Hafez**
}

\author{
Ammar Abdul-kareem Dae'r***
}

\section{ABSTRACT}

Aim of study: The purpose of this study was to evaluate the effects of Modified Tandem Appliance (MTA) in management of Class III cases due to maxillary retrusion. Material and method: Ten female patients with skeletal Class III malocclusion due to maxillary retrusion were selected for this study. The mean age of the patients was 8 years 3 months. All patients were treated with the MTA for one year. Cephalometric radiographs and plaster study models were made at two stages; before and after one year of treatment with the $M \mathcal{A}$ A. The cephalometric radiographs and the study models were analyzed and the collected data were subjected to statistical analysis. $\mathcal{T}$-test was done to determine the significance difference between the pretreatment and posttreatment measurements. Results: The use of $M \mathcal{A}$ A significantly enhanced the forward growth of the maxilla without any noticeable effects on the mandible. The anterior and posterior facial height were significantly increased. There were a significant increase in the proclination of the upper incisors and retroclination of the lower incisors. In addition, there were significant increase in the upper and lower intermolar widths and also, in the upper intercanine width. Conclusion: The MTA was effective in the treatment of skeletal Class III malocclusions due to maxillary retrusion. It had a combination of skeletal and dental effects.

\footnotetext{
* Associate Professor and Head of Orthodontic Department, Faculty of Dentistry, Mansoura University.

${ }^{* *}$ Lecturer of Orthodontics, Faculty of Dentistry, Mansoura University.

${ }^{* * *}$ Clinical Demonstrator in Orthodontic Department, Faculty of Dentistry, Sana'a University.
} 
Egyptian

Orthodontic Journal

\section{INTRODUCTION}

Skeletal Class III malocclusion is one of the most challenging cases for the clinician to manage. ${ }^{1}$ It could be due to maxillary retrusion, mandibular protrusion or combination of both. In Egyptian population, Class III occupies about 10.6 percent. $^{2}$ Treatment of skeletal Class III cases depends on the growth status of the patients. In adult and severe cases orthognathic surgery is the line of treatment. ${ }^{3-4}$ On the other hand, growth appliances have been developed to modify growth in patients with Class III malocclusion. These appliances include maxillary protractors, ${ }^{6-12}$ chin cup, ${ }^{13-16}$ and functional appliances. ${ }^{17-21}$ Maxillary protractors have been used to enhance the growth of the maxilla, while chin cup has been utilized to restrict the mandibular growth. On the other hand, the aim of the functional appliances is to stimulate the forward growth of the maxilla and inhibit the growth of the mandible. . $^{5-21}$

The majority of the previous mentioned appliances impaired the esthetic and cause skin irritation from the anchorage pad. To overcome these problems, Chun et al in 1999 developed an appliance and called it Tandem Traction Bow Appliance (TTBA) for orthopedic correction of Class III malocclusion. ${ }^{22}$ The TTBA was intraoral removable appliance composed of an upper and lower acrylic splints and a traction bow. In 2003 Klempner $^{23}$ modified this appliance to increase its efficiency and termed it Modified Tandem Appliance (MTA). The upper removable acrylic splint of the original appliance was replaced by fixed part consisted of a maxillary banded Hyrax appliance with two hooks for Class III elastics. However, little information were available regarding its effects. ${ }^{23}$ Therefore, this study was conducted to evaluate the dentoskeletal effects of Modified Tandem Appliance in management of Class III cases with maxillary retrusion.

\section{MATERIALS AND METHODS}

\section{Subjects:}

The sample of this study was consisted of ten female patients. The mean age of the patients was 8 years 3 months. The patients were selected according to the following criteria: 
- Skeletal Class III due to maxillary retrusion $(\mathrm{SNA} \leq 80){ }^{24}$

- Growing patients (7 - 9 years).

- No previous orthodontic treatment.

- No abnormal oral habits.

All patients were treated with MTA for one year.

\section{Records:}

For all patients the following diagnostic records were made:

I. Photographs:

A. Intraoral:

1. Frontal view.

2. Lateral views (Right and left).

\section{B. Extraoral:}

1. Frontal view.

2. Lateral view.

II. Upper and lower casts.

III. Radiographs:

A. Lateral Cephalometric radiograph.

B. Panoramic X-ray film.

C. Hand Wrist X-ray film.

All records were made before and after one year of application of modified tandem appliance except the hand wrist and panoramic x-ray films which were taken only before treatment. Hand wrist X-ray films were used to assess the skeletal age. All patients had no sign of calcification of the adductor sesamoid. On the other hand, panoramic $\mathrm{x}$-ray films were utilized to distinguish if there is any pathological condition, root resorption, alveolar bone resorption, supernumerary tooth, and congenital missing tooth. 
Egyptian

Orthodontic Journal

\section{Lateral cephalometric X-ray analysis:}

The pretreatment and posttreatment cephalometric x-ray films were traced on acetate paper. Then the cephalometric points (landmarks), lines and planes were determined. ${ }^{25,26}$

\section{Cephalometric points:}

- N (Nasion): The most anterior point of the nasofrontal suture.

- S (Sella): The center of sella turcica.

- A Point or (Subspinale): The deepest midline point in the curved bony outline from the base to the alveolar process of the maxilla, i.e. at the deepest point between the anterior nasal spine and prosthion.

- B Point (Supramentale): The most posterior point in the outer contour of the mandibular alveolar prosess, in the median plane. It is between infradentale and pogonion.

- Pg (Pogonion): The most anterior point on the bony chin, in the median plane.

- Me (Menton): The most caudal point in the outline of the symphysis; it is regarded as the lowest point of the mandible and corresponds to the anthropological gnathion.

- Go (Gonion): The intersection of the lines tangent to the posterior margin of the ascending ramus and the mandibular base.

- ANS (Anterior nasal spine): It is the tip of the bony anterior nasal spine, in the median plane.

- PNS (Posterior nasal spine): This is a constructed radiographical point, the intersection of a continuation of the anterior wall of the pterygopalatine fossa and the floor of the nose. It marks the dorsal limit of the maxilla.

- ii (incision inferius): The incisal tip of the most prominent mandibular central incisor.

- is (incision superius): The incisal tip of the most prominent maxillary central incisor.

- mi (molar inferius): The mesial contact point of the mandibular permanent first molar determined by a tangent perpendicular to OL; where double projection gives rise to two points, the midpoint was used. 
- ms (molar superius): The mesial contact point of the maxillary permanent first molar determined by a tangent perpendicular to OL; where double projection gives rise to two points, the midpoint was used.

\section{Cephalometric lines and planes:}

- OL (occlusal line): A line through is (incision superius) and the distobuccal cusp of the maxillary permanent first molar. The line from the initial head film was used as reference line for measurements on all head films.

- OLp (occlusal line perpendiculare): A line perpendicular to OL through s. The line from the initial head film was used as reference line for measurements on all head films.

- SN (nasion-sella line): The line through $\mathrm{N}$ and $\mathrm{S}$. The line was used for orientation of all head films.

- MP (mandibular plane): It extended from Me to Go.

- PP (Palatal Plane): It extended from ANS to PNS.

- N-Me: Anterior facial height.

- S-Go: Posterior facial height.

\section{Measuring procedures:}

The occlusal line (OL) and the occlusal line perpendiculare (OLp) from the first head film were used as a reference grid for all linear measurements on the centric occlusion roentgenograms. ${ }^{68}$ The grid was transferred from the first tracing to the following tracings by superimposition of the tracings on the sella-nasion line (SN) with sella $(\mathrm{S})$ as registering point. All registrations were done parallel with OL to OLp.

\section{Linear measurements:}

- is/OLp: A line passing from is to OLp.

- ii/OLp: A line passing from ii to OLp.

- Overjet: is/OLp-ii/OLp

- A/OLp: A line passing from A to OLp.

- Pg/OLp: A line passing from Pg to OLp. 
- ms/OLp: A line passing from ms to OLp.

- mi/OLp: A line passing from mi to OLp.

II. Angular measurements:

- SNA: Anteroposterior position of the maxilla relative to the anterior cranial base.

- SNB: Anteroposterior position of the mandible relative to the anterior cranial base.

- ANB: Difference between SNA and SNB.

- MP-SN: Angle between SN and mandibular plane. It gives the inclination of the mandible to the anterior cranial base.

- PP-SN: Angle between SN and palatal plane.

- U1-SN: The posterior angle formed by extending the long axis of the upper incisor to intersect the SN line.

- L1-MP: The posterior angle between the long axis of the lower central incisor and mandibular plane.

- U1-L1 angle (inter-incisal angle): The angle between the long axis of the maxillary and mandibular incisors.

\section{Casts analysis:}

In the upper and lower plaster casts the following measurements were done using Boly gauge graduated to the nearest $0.1 \mathrm{~mm}$ :

I. The intermolar width: The distances between the mesiobuccal cusp tips of the first permanent molars.

II. The intercanine width: The distance between the cusp tips or estimated cusp tips in cases of wear facets.

III. Overjet: The distance from the incisal edge of the most protruded maxillary incisor to that of the opposing mandibular central incisor tooth.

IV. Overbite: The vertical overlap of the lower incisors by the upper incisors. 


\section{Appliance construction:}

The Modified Tandem Appliance was designed according to Klempner. ${ }^{23}$ It consisted of two main parts; maxillary and mandibular.

\section{Maxillary part:}

It incorporated a hyrax expander (Leone, Italy) which was adapted in palatal area and soldered to bands (Ortho Organizer, USA) on the maxillary first molars. Buccal arms made of $0.9 \mathrm{~mm}$ stainless steel round wire were soldered to the buccal sides of the molar bands and extended anteriorly to the canine region and used for elastic traction.

\section{Mandibular part:}

It consisted of a lower acrylic removable appliance with posterior bite plane. It incorporated Adams and "C" clasps made of $0.7 \mathrm{~mm}$ stainless steel wire (Dentaurum, Germany) were constructed on the permanent first molars and deciduous canines respectively for retention. Also, headgear tubes were embedded in the acrylic occlusal coverage at the molar region. A facebow (Leone, Italy) was adjusted to be easily inserted in the headgear tubes. However, the outer bow was modified to be in the form of anterior hooks for elastic attachments (Figure 1).

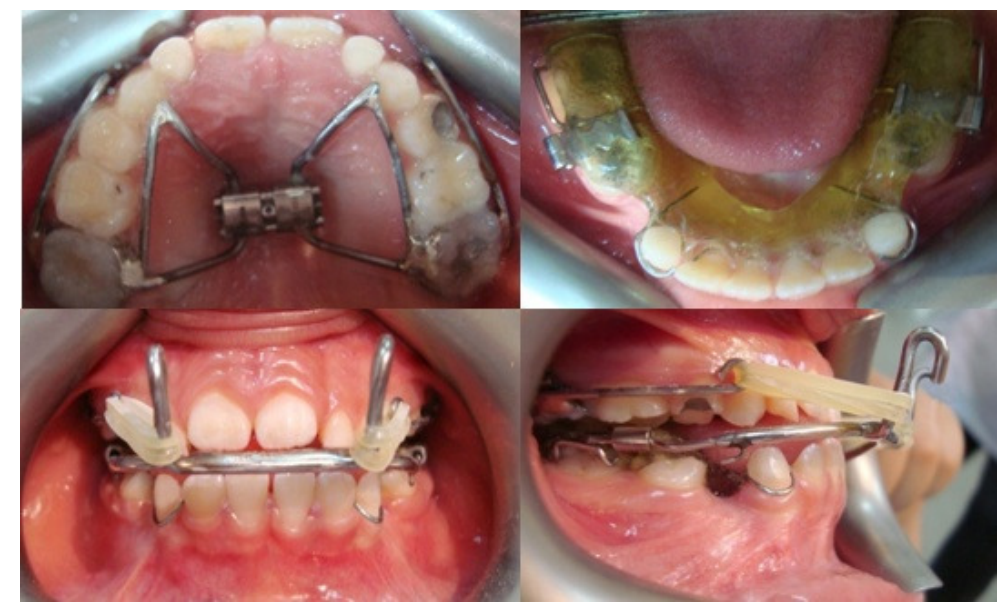

Figure1: The Modified Tandem Appliance. 


\section{Appliance insertion and activation:}

The maxillary appliance (hyrax \& buccal arms) was cemented using glass ionomer cement (Ortho Organizer, USA). Then the lower appliance was inserted. After one week, heavy orthopedic elastic traction (American Ortho, USA) was applied from the anterior hooks of the facebow to the buccal arms of the upper fixed appliance. The traction force was 400 grams per side. This step was done with the aid of a force gauge (Somfy tec, France). The patients were followed up every three weeks and checked for any problem. The patients and parents were instructed to clean the appliance daily with tooth brush and mouth wash, change the elastics every day, turn the hyrax expander two quarter turn per week and to wear the appliance more than 14 hours/day (Figure 2 and 3 ).

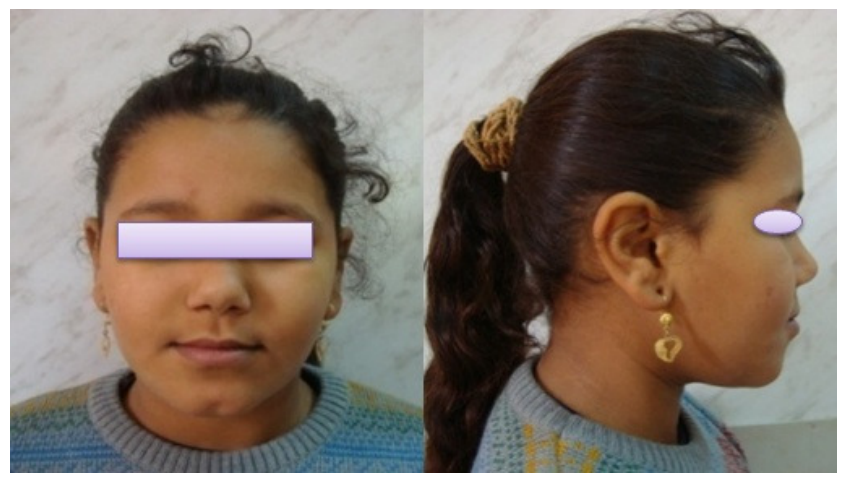

Pretreatment

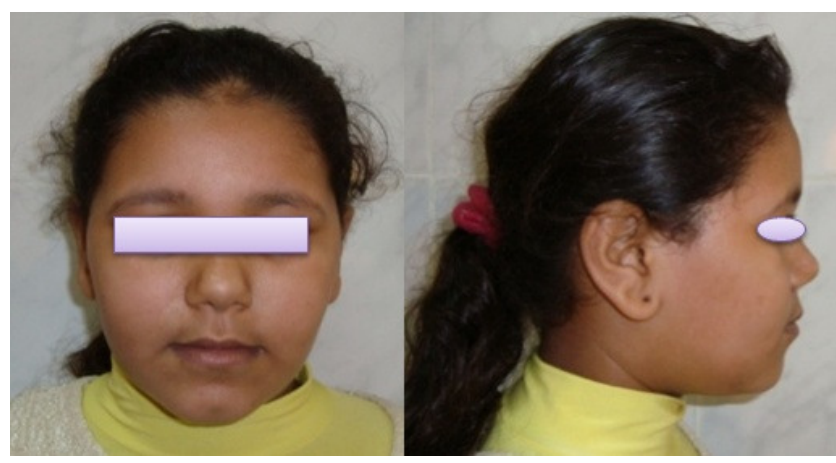

Posttreatment

Figure 2: Extraoral photographs of patient treated with MTA. 


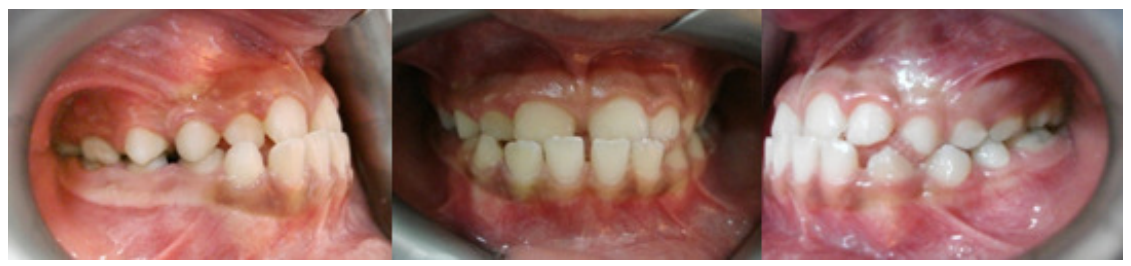

Pretreatment

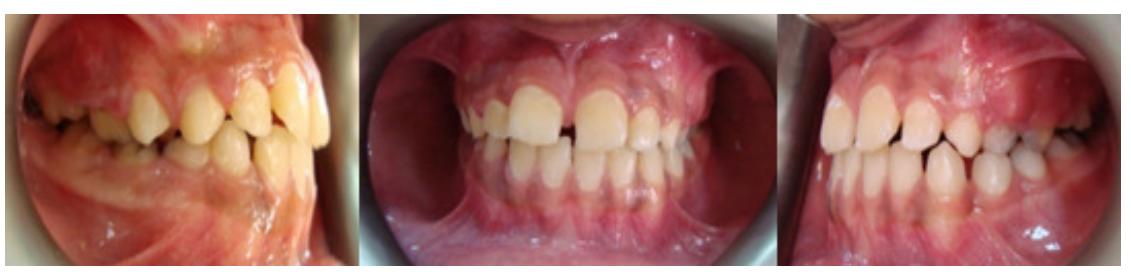

Posttreatment

Figure 3: Intraoral photographs of patient treated with MTA.

\section{Statistical analysis}

All measurements were calculated and analyzed using the SPSS statistical program (Chicago, Il). Descriptive statistics including means and standard deviations of the measurements before and after treatment were obtained. Then, t-test was done to test the significance difference between the pretreatment and posttreatment measurements. Significance for the statistical test was predetermined at $\mathrm{P}<0.05$.

\section{RESULTS}

The means, standard deviations and the results of t-test of the pretreatment and posttreatment cephalometric measurements are presented in Table I. The results revealed that, the maxillary forward growth was stimulated as the SNA angle and AlOLp length were significantly increased $(\mathrm{P}=.000)$. On the other hand, the mandibular growth was not affected. The SNB angle and Pg/OLp length were not significantly changed $(\mathrm{P}=.626 \& \mathrm{P}=.081$ respectively). The maxillary mandibular relationship (ANB angle) was significantly improved $(\mathrm{P}=.003)$. The mandibular plane angle (SN-MP) and palatal plane angle (SN-PP) were not significantly affected $(\mathrm{P}=.824 \& \mathrm{P}=.068$ respectively). On the other hand, the anterior and 
posterior facial heights (N-Me \& S-Go respectively) were increased significantly $(\mathrm{P}=.001 \& \mathrm{P}=.000$ respectively).

Regarding the dental measurements, the overjet (is/OLp - ii/OLp) was significantly improved $(\mathrm{P}=.000)$. There was a significant proclination of upper incisors as is/OLp length and U1/SN angle were increased $(\mathrm{P}=.000 \& \mathrm{P}=.016$ respectively $)$. In addition, there was a noticeable retroclination of the lower incisors as L1/MP angle was significantly decreased $(\mathrm{P}=.006)$. The maxillary first molars showed significant mesial movement as the ms/OLp length was significantly increased $(\mathrm{P}=.000)$. However, the mandibular molar position (mi OLp length) showed a non significant change $(\mathrm{P}=.182)$. The upper and lower molar relationship (ms $\backslash$ OLp-mi $\backslash$ OLp length) was significantly improved $(\mathrm{P}=.000)$.

Table I: The means, standard deviations (SD), and the results of t-test of the pretreatment and posttreatment cephalometric measurements.

\begin{tabular}{|l|c|c|c|c|}
\hline \multirow{2}{*}{ Measurements } & Pretreatment & Posttreatment & \multirow{2}{*}{ t } & \multirow{2}{*}{ p-value } \\
\cline { 2 - 3 } & Mean \pm SD & Mean \pm SD & & \\
\hline SNA (degree) & $78.60 \pm 0.94$ & $80.30 \pm 1.48$ & -5.667 & .000 \\
\hline SNB (degree) & $80.05 \pm 1.01$ & $79.80 \pm 1.21$ & 0.504 & .626 \\
\hline ANB (degree) & $-1.45 \pm 1.09$ & $00.50 \pm 1.96$ & -4.064 & .003 \\
\hline A/OLp (mm) & $62.17 \pm 2.06$ & $65.81 \pm 2.53$ & -8.964 & .000 \\
\hline Pg/OLp (mm) & $71.00 \pm 2.08$ & $71.05 \pm 2.11$ & -1.963 & .081 \\
\hline SN-MP (degree) & $38.28 \pm 1.56$ & $38.45 \pm 2.72$ & -0.23 & .824 \\
\hline SN-PP (degree) & $7.70 \pm 2.06$ & $6.80 \pm 2.10$ & 2.01 & .068 \\
\hline N-Me (mm) & $100.55 \pm 3.32$ & $103.32 \pm 2.78$ & -4.76 & .001 \\
\hline S-Go (mm) & $59.27 \pm 3.30$ & $61.58 \pm 3.06$ & -5.39 & .000 \\
\hline Overjet (mm) & $-1.42 \pm 1.24$ & $1.70 \pm 1.46$ & -5.78 & .000 \\
\hline U1/SN (degree) & $111.90 \pm 2.02$ & $115.80 \pm 2.25$ & -2.95 & .016 \\
\hline L1/MP (degree) & $86.97 \pm 6.27$ & $84.25 \pm 8.03$ & 3.54 & .006 \\
\hline is/OLp (mm) & $70.22 \pm 2.88$ & $74.99 \pm 3.27$ & -6.63 & .000 \\
\hline ii/OLp (mm) & $73.29 \pm 2.89$ & $71.64 \pm 2.78$ & 1.61 & .143 \\
\hline ms/OLp (mm) & $42.07 \pm 1.04$ & $48.22 \pm 1.75$ & -10.52 & .000 \\
\hline mi/OLp (mm) & $48.32 \pm 1.33$ & $49.72 \pm 3.73$ & -1.45 & .182 \\
\hline $\begin{array}{l}\text { ms/OLp-mi/OLp } \\
\text { (molar relationship)(mm) }\end{array}$ & $-6.25 \pm 1.31$ & $-1.50 \pm 2.47$ & -6.24 & .000 \\
\hline Significant: P<0.05 & & & & \\
\hline
\end{tabular}

Significant: $\mathrm{P}<0.05$ 
The means, standard deviations and the results of t-test of the pretreatment and posttreatment measurements of dental cast are illustrated in Table II. There was a significant correction of the over jet $(p=.000)$. The overbite showed a significant decrease $(\mathrm{P}=.000)$. The upper intercanine widths was significantly increased $(\mathrm{P}=.040)$. Finally, there were a significant increase in upper and lower intermolar widths $(\mathrm{P}=.039 \& \mathrm{P}=.017$ respectively).

Table II: The means, standard deviations (SD), and the results of t-test of the pretreatment and posttreatment measurements of dental casts.

\begin{tabular}{|l|c|c|c|c|}
\hline \multirow{2}{*}{ Measurements } & Pretreatment & Posttreatment & \multirow{2}{*}{ t } & p-value \\
\cline { 2 - 3 } & Mean \pm SD & Mean \pm SD & & \\
\hline Overjet $(\mathrm{mm})$ & $-1.11 \pm 0.49$ & $1.44 \pm 0.42$ & -9.18 & .000 \\
\hline Overbite \% & $32.30 \pm 3.56$ & $27.60 \pm 3.13$ & 11.11 & .000 \\
\hline UICW $(\mathrm{mm})$ & $30.40 \pm 1.38$ & $32.00 \pm 2.65$ & -1.89 & .040 \\
\hline LICW $(\mathrm{mm})$ & $25.71 \pm 1.50$ & $26.00 \pm 1.53$ & -1.00 & .356 \\
\hline UIMW $(\mathrm{mm})$ & $43.07 \pm 1.97$ & $44.93 \pm 2.23$ & -2.63 & .039 \\
\hline LIMW $(\mathrm{mm})$ & $40.29 \pm 1.98$ & $41.14 \pm 1.95$ & -3.29 & .017 \\
\hline
\end{tabular}

Significant: $\mathrm{P}<0.05$

$\mathrm{UICW}=$ Upper intercanine width.

LICW= Lower intercanine width.

UIMW= Upper intermolar width.

LIMW= Lower intermolar width.

\section{DISCUSSION}

The present study was conducted to evaluate the effects of the MTA in management of Class III cases due to maxillary retrusion. The sample selection was made with special criteria. It was done with respect to basic factors which could influence the treatment results. These factors included; sex, ethnic background, skeleto-facial morphology, and growth status. The study was limited to growing Egyptian female patients, as females and males behave differently not only in timing of maximum pubertal growth but also in response to the same appliance therapy. ${ }^{28,29}$ Also, all patients had skeletal Class III malocclusion due to maxillary retrusion. The cephalometric analysis was done according to Pancherz. In this method the original OL and OLp are used for both before and after treatment measurements, hence the tipping of the OL plane during the treatment period will not influence the reference system and bias the measurements. ${ }^{25}$ 
Egyptian

Orthodontic Journal

\section{Skeletal effects:}

\section{Maxilla}

The utilization of Modified Tandem Appliance had stimulated the maxillary growth. A significant increase in the SNA angle and the A $\backslash$ OLp length were found. This result was in agreement with other protractor appliances studies of McNamara ${ }^{6}$, Kajiyama et al. ${ }^{12}$, Chun et al. ${ }^{22}$, Klempner ${ }^{23}$, Ngan et al. ${ }^{30}$, and Williams et al. ${ }^{31}$. On the other hand, it was in contrast to the results of Tuncer and Uner $^{21}$ who utilized the magnetic appliance for management of Class III. This dissimilarity in the findings might be explained by the difference in the appliance design.

\section{Mandible}

In the present study, unnoticeable effect on the mandibular growth was found. The SNB angle and Pg/OLp length were not significantly changed. According to Proffit, heavy force for long duration (more than children could tolerate) could be needed to restrict the mandibular growth. ${ }^{32}$ This finding was in harmony with Klempner ${ }^{23}$. However, it was in disagreement with the findings of Campbell ${ }^{1}$, McNamara ${ }^{6}$, Chun et al. ${ }^{22}$, Ngan et al. ${ }^{30}$, and Williams et al. ${ }^{31}$. This controversy could be attributed to the difference of the appliance design between the Modified Tandem Appliance and the other protractor appliances.

\section{Maxillomandibular relationship}

In the current study, maxillomandibular relationship was improved as the ANB angle was significantly increased. This outcome was in agreement with those of Satravaha and Taweesedt ${ }^{33}$, and Üçüncü et al. ${ }^{34}$ The increase in SNA angle was responsible for the increase in ANB angle and the maxillomandibular relationship.

\section{Vertical dimension}

Regarding the vertical dimension, the use of Modified Tandem Appliance led to a significant increase in the anterior and posterior facial heights (N-Me \& S-Go respectively). This could be contributed to the use of maxillary expander screw. ${ }^{27}$ These results were in agreement with those of Altug and Arslan ${ }^{7}$, Kidner et al. ${ }^{18}$, Klempner ${ }^{23}$, and Ngan et al. ${ }^{30}$. On the other hand, the mandibular and palatal plane angles were not 
significantly changed. This could be explained by, the Modified Tandem Appliance incorporate a posterior bite plane. Also, a proportional increase might occur in both the anterior and posterior height.

\section{Dental effects:}

\section{Incisors}

In the present study, the upper incisors showed a noticeable anterior movement and proclination as is/OLp length and U1/SN angle were increased significantly. Similar findings were reported in maxillary protractor studies of Campbell ${ }^{1}$, McNamara ${ }^{6}$, Altug and Arslan ${ }^{7}$, Kajiyama et al. ${ }^{12}$, Kidner et al. ${ }^{18}$, Ngan et al. ${ }^{30}$, and Williams et al. ${ }^{31}$.

Regarding the lower incisor position, there was a retroclination of the lower incisors as L1/MP angle was significantly decreased. However, a non significant change in the lower incisor edge position in the anteroposterior direction was found. The ii/OLp length was not significantly changed. This result was in agreement with those of Campbel1 ${ }^{1}$, McNamara ${ }^{6}$, Altug and Arslan ${ }^{7}$, Kidner et al. ${ }^{18}$, and Ngan et al. ${ }^{30}$.

The overjet in the cast and cephalometric analyses was significantly improved. This finding was in accordance with those of Altug and Arslan ${ }^{7}$, Fuly et al. ${ }^{20}$, Tuncer and Uner ${ }^{21}$, Ngan et al. ${ }^{30}$, and Üçüncü et al. ${ }^{34}$. This could be attributed to skeletal and dental changes. The skeletal changes involved a significant forward movement of the maxilla. The dental changes were attributed to the proclination of the upper incisors and retroclination of the lower incisors.

In the current study, the overbite was significantly decreased. Altug and Arslan ${ }^{7}$, Tuncer and Uner ${ }^{21}$, and Ngan et al. ${ }^{30}$ showed a similar result. This might be a result of the force that was likely to be below the center of resistance of the maxilla and also because of the use of expansion screw.

\section{Molars}

The maxillary first molars showed significant mesial movement as the ms/OLp length was significantly increased. This could be attributed to the forward movement of the maxilla and mesial movement of the molars within the maxilla. 
Regarding the position of the lower molars, non significant change was found as the milOLp length showed a non significant result. This could be explained by the appliance design which incorporated lower acrylic part with posterior bite plane that splitting the teeth and increase the anchorage in the molar region. In addition, no significant change was found in the mandibular position.

The upper and lower molar relationship was improved. The ms $\backslash O L p-$ mi $\backslash$ OLp length was significantly increased. This was in agreement to that of Üçüncü et al. ${ }^{34}$ This could be attributed to the mesial movement of the upper molars found in the present study.

The upper intermolar and intercanine widths (UIMW \& UICW) and lower intermolar width (LIMW) showed a significant increase. These were expected results due to the use of maxillary expender. On the other hand, the lower intercanine showed a non significant change.

\section{Clinical evaluation}

Considering the clinical point of view, the Modified Tandem Appliance was esthetically acceptable for the patient as it impaired the facial esthetic less than other protractor appliance such as the face mask of Delaire or of Petit. However, the speech of the patients was affected in the first week after appliance insertion. Also, dislodgement of the mandibular part of the appliance was a common problem during the vertical movement of the mandible especially in the first month of treatment. This dislodgement occurred in spite the use of Adams' and C-clasps.

\section{Conclusion}

From this study the followings were concluded:

- The modified Tandem Appliance could be used effectively in management of skeletal Class III malocclusions due to maxillary retrusion.

- It had a combination of skeletal and dental effects.

\section{REFERENCES}

1. Campbell PM. The dilemma of class III treatment: Early or late? Angle Orthod 1983;53:175-191. 
2. El-Mangoury NH, Mostafa YA. Epidemiologic panorama of dental occlusion. Angle Orthod 1987;60:207-214.

3. Neto JR, Paiva JBD, Junior HM, Attizzani MF. Surgical-Orthodontic Treatment of a Class III Dentofacial Deformity. J Clin Orthod 2007;6:331-335.

4. Chew MT. Soft and Hard Tissue Changes after Bimaxillary Surgery in Chinese Class III Patients. Angle Orthod 2005;75:959-963.

5. Iida Y, Sr TD, Kageyama T. Chin Cup Treatment Outcomes in Skeletal Class III Dolicho- Versus Nondolichofacial Patients. Angle Orthod 2005;75:576-583.

6. McNamara JA. An orthopedic approach to the treatment of Class III malocclusion in young patients. J Clin Orthod 1987;21:598-608

7. Altug Z, Arslan AD. Skeletal and Dental Effects of a Mini Maxillary Protraction Appliance. Angle Orthod 2006;76:360-368.

8. Hickham JH. Maxillary protraction therapy: diagnosis and treatment. J Clin Orthod 1991;25:102-113.

9. Kircelli BH, Pektas ZO. Midfacial protraction with skeletally anchored face mask therapy: A novel approach and preliminary results. Am J Orthod Dentofacial Orthop 2008;133:440-449.

10. Conte A, Carano A, Siciliani G. A new maxillary protractor. J Clin Orthod 1997;31:523-530.

11. Nik TH, Noroozi H. Design and fabrication of a modified protraction headgear for Class III long face patients. Am J Orthod Dentofacial Orthop 1999;115:553-558.

12. Kajiyama K, Murakami T, Suzuki A. Evaluation of the modified maxillary protractor applied to Class III malocclusion with retruded maxilla in early mixed dentition. Am J Orthod Dentofacial Orthop 2000;118:549-559.

13. Bernstein M. The Use of the CHIN CAP in Class III Therapy. J Clin Orthod 1968; Apr:172-173. 
14. Vego L. Early orthopedic treatment for Class III skeletal patterns. Am J Orthod 1976;70:59-69.

15. Graber LW. Chin cup therapy for mandibular Prognathism. Am J orthod 1977;72:23-41.

16. Mitani H, Sakamoto T. Chin Cap Force to a Growing Mandible: Long-term clinical reports. Angle Orthod 1984;54:93-122.

17. Miethke RR, Lindenau S, Dietrich K. The effect of Fränkel's function regulator type III on the apical base. Eur J Orthod 2003; 25: 311-318.

18. Kidner G, DiBiase A, DiBiase D. Class III Twin Blocks: a case series. Journal of Orthodontics 2003;30:197-201.

19. Giancotti A, Maselli A, Mampieri G, Spanò E. Pseudo-Class III malocclusion treatment with Balters' Bionator. Journal of Orthodontics 2003; 30:203-215.

20. Fuly CDM, Oliveira AGD, Ursi W. Correction of Class III Malocclusion with a Jasper Jumper. J Clin Orthod 2000;34:41-46.

21. Tuncer C, Uner O. Effects of a Magnetic Appliance in Functional Class III Patients. Angle Orthod 2005;75:768-777.

22. Chun YS, Jeong SG, Row J, Yang SJ. A new appliance for orthopedic correction of Class III malocclusion. J Clin Orthod 1999; 32:705-711.

23. Klempner LS. Early Orthopedic Class III Treatment with a Modified Tandem Appliance. J Clin Orthod 2003;37:218-223.

24. Abdulla EMA. Comparison of Various Dental and Facial Parameters Between Egyptian and American Adolescents. Partial Fulfillment of the Requirements for Doctor Degree in Orthodontics. 1986 Alexandria University, Faculty of Dentistry.

25. Pancherz H. The mechanism of Class II correction in Herbst appliance treatment; A cephalometric investigation. Am J Orthod Dentofacial Orthop 1982;Aug:104-113.

26. Rakosi T. An Atlas and Manual of Cephalometric Radiography, Wolfe Medical Publications Ltd, 1982. 
27. Bishara SE, Staley RN. Maxillary expansion: Clinical implications. Am J Orthod Dentofacial Orthop 1987;91:3-14.

28. Pfeiffer JP. Should orthopaedic treatment of severe Class II malocclusion be related to growth?. Eur J Orthod 1980;2:249-256.

29. Pfeiffer JP, Grobety D. Simultaneous use of cervical appliance and activation: an orthopaedic approach to fixed appliance therapy. Am J Orthod 1972;61:353-373.

30. Ngan P, Wei SHY, Hagg U, Yiu CKY, Merwin D, Stickel B. Effect of protraction headgear on Class III malocclusion. Quintessence Int 1992;23:197-207.

31. Williams MD, Sarver DM, Sadowsky PL, Bradley E. Combined rapid maxillary expansion and protraction facemask in the treatment of Class III malocclusions in growing children: a prospective long-term study. Semin Orthod 1997;3:265-274.

32. Proffit WR, Fields HW, Ackerman JL. Contemporary Orthodontics. St Louis: Mosby; Third edition 2000 p.513-518.

33. Satravaha S, Taweesedt N. Stability of skeletal changes after activator treatment of patients with Class III malocclusions. Am J Orthod Dentofacial Orthop 1999;116:196-206.

34. Üçüncü N, Üçem TT, Yüksel S. A comparison of chincap and maxillary protraction appliances in the treatment of skeletal Class III malocclusions. Eur J Orthod 2000;22:43-51. 